\title{
Certification of addiction professionals in Africa: an overview of the process in Kenya
}

Richard M. Gakunju KCAC III', George Murimi KCAC III' ${ }^{1}$

${ }^{1}$ Kenya Certification Council, Kenya.

Correspondence email: drrgakunju@gmail.com

\begin{abstract}
This paper focuses on Kenya's course of action to address the drug problem, specifically, treatment and rehabilitation of persons with Substance Use Disorders (SUDs). Treatment and rehabilitation of persons with SUDs was formally initiated in Kenya in 1978 and has grown since early 2000. Kenya national strategy on prevention, control and mitigation of drug and substance abuse in 2009 highlighted the essence of provision of quality, comprehensive and holistic care programmes to drug users and their immediate families. According to the 2009 - 2014 National Campaign Against Alcohol and Drug Abuse (NACADA's) strategic plan, there was a need to improve the overall legal framework on treatment of SUDs. Thus certification process and National Standards were established so that practices are consistent with international guidelines of services offered by treatment providers. To improve treatment and rehabilitation, one must ensure that the people who work in drug addiction related matters in Kenya are not only trained but also licensed to practice based on their level of education, training and supervised experience. This paper outlines the training, examination and certification of Kenyan service providers to provide standard and quality services to treat and rehabilitate SUDs.
\end{abstract}




\section{شهادات المختصين في الإدمان في أفريقيا:نظرة عن العملية في كنيا الدكتور ريتشرد م. قاكونجو، رئيس المجلس الكيني للشهادات جورج موريمي، أمين سر، المجلس الكيني للشهادات}

الملخص:

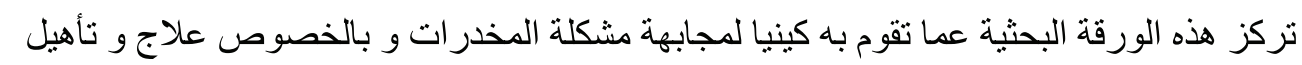

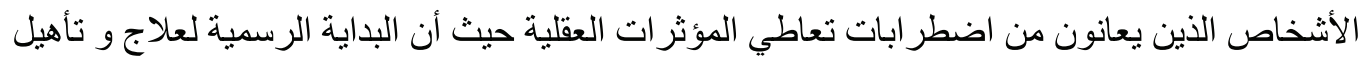

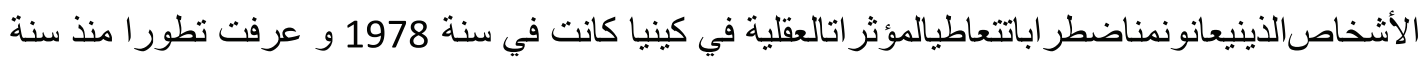

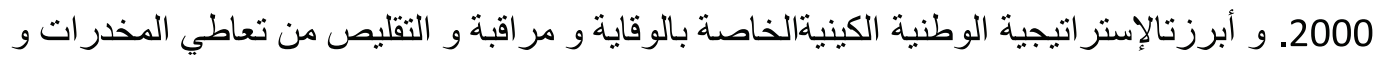

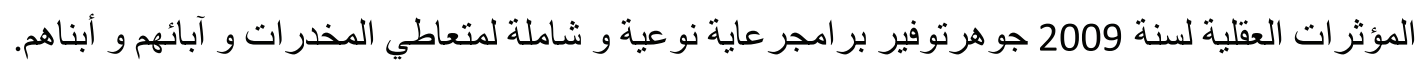

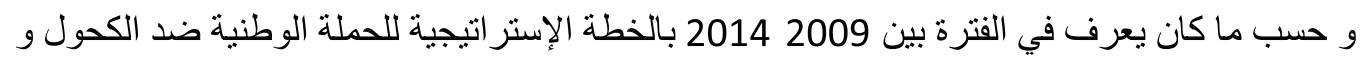

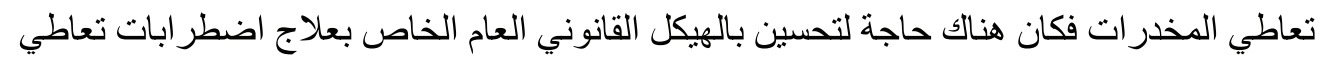

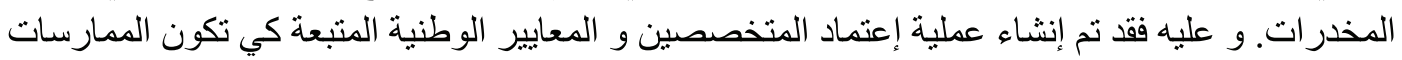

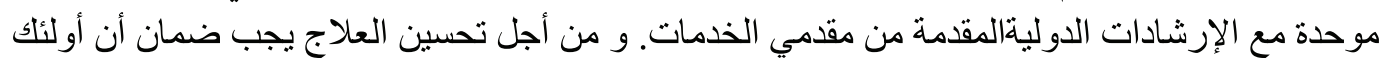

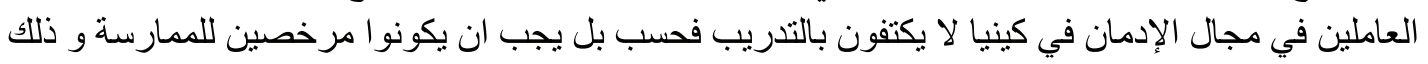

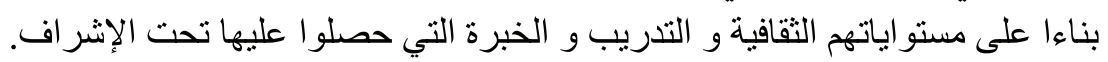

تلقي هذه الورقة البحثية الضوء على التدريب و اختبار و اعتماد مقدمي الخدمات في كينيا بغية تقديم خدمات معيارية و نو عية لعلاج و تأهيل أولئك الذينيعانو نمناضطر اباتئتعاطيالمؤثر اتالعقلية.

Keywords: SUDs, Substance use disorders, UNODC world drug reports

\section{Introduction}

Africa is the second largest and the second most populous continent in the world with a population of about 1.111 billion people. ${ }^{1}$ The World Health Organisation (WHO) and UNODC World Drug reports indicate that the continent has not been spared the problem of drug abuse and trafficking. For instance, in West and Central Africa, the incidence of cannabis consumption is at $12.4 \%$ (a much higher level than the global average of 3.8\%). Amphetamine-Type Stimulants (ATS), cocaine and heroin use are also on the rise; suffice to say that reliable and comprehensive information on the drug situation in Africa is barely available. ${ }^{2}$ Documentations, such as this paper, will reduce the existing gap.

This paper will focus on what Kenya is doing in order to address the drug problem: treatment and rehabilitation of persons with SUDs. Most particu- 
larly in developing a cadre of professionals in the field who can ensure that desired treatment outcomes are achieved.

Treatment and rehabilitation of persons with SUDs was formally initiated in Kenya around 1978 and has grown exponentially since early $2000 .^{3,4}$ Despite the growing need for treatment and rehabilitation, there is still a deficit of affordable treatment facilities as well as competent professionals to undertake responsibility. Qualifications of the current service providers have been largely gone undocumented and therefore given no guarantee on professionalism or the quality of professionals undertaking treatment and rehabilitation services in Kenya.

The Kenya National Strategy on Prevention, Control and Mitigation of Drug and Substance Abuse of 2009 highlighted the essence of provision of quality, comprehensive and holistic care programme to drug users and their immediate families.

The Kenya National Drug Control Master Plan of 2000, on the other hand, identified the need for establishing a sub committee responsible for developing, monitoring and evaluating a comprehensive national (including public and private sectors) treatment and rehabilitation policy for drug addiction. The policy would be based on an analysis of available information leading to an identification of target groups, existing human and physical resources, and an evaluation of the most efficient methods of integrating the programmes into the existing health and social structures such as the primary health care system.

According to the then National Campaign against NACADA's strategic plan 2009 - 2014, there was a need to improve on professionalism and the perception of treatment facilities both from the public and persons with SUDs. Secondly, NACADA sought to improve the availability, affordability and quality of treatment as well as to improve the overall legal and policy frameworks on treatment of persons with SUDs.

The strategic plan further stated that NACADA would guide and monitor implementation of the standards and develop clear certification criteria. This would aid in the process of regularising treatment and rehabilitation care in the country.

The objective of the certification process and the national standards was to promote professionalism and establish best practices consistent with international guidelines namely: to improve transparency, consistency, comparability, completeness and confidence in services offered by treatment providers. To accomplish this, a certification body would be formed to expedite the 
certification process and oversee quality assurance.

The national standards on treatment and rehabilitation of persons with SUDs was developed in 2009 to address best practices in the treatment and rehabilitation of such persons that would include their families and significant others. One of these was certification.

Certification is defined as a process by which an agency evaluates a person according to pre-determined professional standards. Whereas certification applies to people, a similar term; accreditation applies to institutions. ${ }^{5}$ Certification in the field of drug dependence treatment, therefore, is a process that sets the minimum competency requirements to diagnose and treat persons with SUDs and aims to consistently achieve superior results. Patients, physicians, healthcare providers, insurers and quality organisations will refer to the certification process as a means of measuring a professional's knowledge, experience and skills to provide quality care. The objective of this exercise is to give an opportunity to addiction professionals in Kenya to enrol and participate in the certification process and receive credentials required for professional practice.

The essence of the process has been to ensure that the people who work in matters relating to 'addiction' in Kenya are not only trained but also licensed to practice based on their level of education, training and supervised experience. Only then, can professionalism and professional development be assured. Clients, therefore, will be in the hands of qualified and competent personnel who can guarantee quality.

This issue of certification is raised in the standards document as follows: ${ }^{6}$

9.5.2 Staff qualifications and registration: Facilities employ only professional, accredited and administrative staff with the appropriate accredited and recognised professional qualifications. All professional staff is appropriately registered with an official professional or accrediting body. The minimum qualification for the clinical team is a diploma in their areas of specialisation.

9.5.3 Staff composition: Treatment facilities will have the following composition of staff:

a. A medical doctor/ psychiatrist and a nurse are employed or are on call for 24-hour backup and consultation.

b. The minimum multi-disciplinary team consists of a social worker, clinical/counselling psychologist, accredited addiction counsellor and a trained nurse. 
c. Where detoxification is carried out, a multi-disciplinary team will consist of a medical doctor, a psychiatrist and a trained nurse.

Having established the basis on which certification in Kenya was founded, we can now move on to the historical developments of the certification process; 26 - 30 January 2009 becomes the best time period to begin.

During this period, the first training of 24 Kenyans with American partners was conducted at the Kenya Institute of Administration (KIA), sponsored by the Government of USA through the International Narcotics and Law Enforcement Agency (INL). This inaugural training identified the acute need of introducing a credentialing system which ensures that the people who work in matters related to addiction are competent. During the training, participants had an opportunity to sit for NAADAC and NCAC I examinations in which certification credentials for NCAC I and basic levels were issued to some participants upon the marking of the examinations by the Professional Testing Centre. Professional and academic papers were forwarded to the USA-based NAADAC.

The NAADAC credentialing criteria which were presented then and has been the precedence for Kenya is as follows:

National Certified Addiction Counsellor, Level I (NCAC I): A national certification intended for professionals working within addiction related disciplines who wish to demonstrate their skills gained through years of supervised work experience.

- To qualify for the NCAC I certification, one must have:

- A current State certificate or license as a substance abuse counsellor.

- A total of 270 contact hours of substance abuse counselling training, including six hours of ethics training and six hours of HIV/AIDS training.

- Three years full-time work experience or 6,000 hours of supervised experience as a substance abuse counsellor.

- Evidence of ethics and HIV/AIDS training/education received in the past five years (for new applicants).

National Certified Addiction Counsellor, Level II (NCAC II): A national certification intended for professionals working within addiction related disciplines who wish to demonstrate their specialised addiction treatment skills gained through years of supervised work experience and specific undergraduate coursework. 
To qualify for the NCACII certification, one must meet the following criteria:

- A Bachelor's degree from an accredited college or university.

- A current State certificate or license in an applicable profession.

- A total of 450 contact hours of substance abuse education and training, including six hours of ethics training and six hours of HIV/AIDS training.

- Five years full-time experience or 10,000 hours of supervised experience as a substance abuse counsellor.

- Evidence of Ethics and HIV/AIDS training/education received in the past five years (for new applicants).

Master Addiction Counsellor (MAC): A national certification intended for professionals working within addiction-related disciplines who wish to demonstrate their specialised addiction treatment skills gained through years of supervised work experience and specific graduate coursework.

To qualify for the MAC, one must have attended:

- A total of 500 hours of education and training to include a Master's degree in the healing arts - counselling, social work, family therapy, nursing, psychology, or any other humanitarian services.

- A current State certificate or license in one's profession, such as a Licensed Professional Counsellor (LPC) or a Licensed Social Worker (LSW).

- Three years of supervised experience $-2 / 3$ of which must be post-master's degree award.

- Evidence of ethics and HIV/AIDS training/education received in the past five years (for new applicants).

The participants also reviewed the applicability of NAADAC Certification Examinations to the Kenyan scenario and suggested possible modifications. Among the suggestions made was use of local names and examples so as to fit within the context of the country. They were also tasked with reviewing the NAADAC curriculum in a bid of contextualising it and providing relevant case studies.

The participants then began to develop the Kenyan Credentialing Process, and came up with the following: 


\section{Mission}

To provide standards and credentials that ensure quality service delivery in the prevention, intervention, treatment and continuing care of substance use disorders.

\section{Scope of practice}

The following is the scope of practice: Ongoing treatment plan, Documentation

Case management, Clinical assessments, Clinical supervision.

Counselling Services include: Individual (relapse prevention), Family; Group pharmacology, Relapse prevention); and Crisis Intervention); Client education (HIV/AIDS, ADHD, relapse prevention); Discharge; Treatment admission and Continuing care.

The performance evaluation and requirements for trainings were also developed. Listed below is what was agreed.
A. Pharmacology
$15 \%$

1. Definition of and its relationship to addiction

2. Drug classification

3. Addiction process

B. Counselling practices $\quad 50 \%$

1. Client evaluation

2. Treatment planning

3. Counselling

4. Patient care

5. Education

6. Continuing care

7. Special issues/populations 
C. Theoretical base of counselling

1. Addiction counselling

2. Human growth and development

3. Behaviour/cognitive/analytic theories

D. Professional issues $10 \%$

1. Law and regulations

2. Ethics

3. Supervision

4. Research and outcome studies

Some of the participants in this training were privileged to form the Kenya Certification Council for Addictions Professionals. Others are playing active roles in government and private sector in the drug dependence field.

The second major step was undertaken from $10^{\text {th }}-15^{\text {th }}$ July 2009 . This was the validation of certification examination for addiction treatment professionals in Kenya at Karen Holiday Homes; INL sponsored the event.

The facilitators were Shirley Beckett Mikell, Director of Certification and Education NAADAC, Sara Lee, Senior Programme Analyst at Alvarez and Associates and Dr. Henry Sallyann, President, Professional Testing Corporation (PTC).

The objectives of the forum were to have validation of the certification examination questions for addictions treatment professionals for Basic Level and Level I; and to validate the Credentials targeting Professionals dealing with SUDs in the country such as Psychiatrists, Pharmacists, Psychologists, Counsellors, Nurses and Social workers.

It was resolved that basic level examination would involve 189 items which were eventually worked to the following proportions: Pharmacology (25\%); Counselling practice (40\%); Theoretical base (25\%) and Professional issues $(10 \%)$.

The criteria for eligibility would be 150 hours of education/training, one year of practical experience and 250 hours of supervision.

The examination would be referred to as basic level and would produce technicians. $^{7}$

Content areas include the following: screening/intake; Orientation; Pre-as- 
sessment; Contribute to Treatment plan; Case Management; Crisis; Education/group education; Documentation; Supervised skills such as individual and group counselling; and Continuing Care.

It is worth noting that the Kenya system has since dropped the basic level credentials since the national standards require minimum of a diploma for the clinical positions. It is envisaged that those with lower qualifications can enrol for other programmes such as the recovery coach that is currently being implemented by the International Centre for Certification and Education of Addictions Professionals (ICCE).

Level I credentials on the other hand, would equip a Clinical Counsellor. The criteria for eligibility is Diploma in one's area of specialisation including 270 hours of training on drugs, three years of hands on experience and 2000 hours of supervised practice.

Level II credentials would produce department heads. The criteria for eligibility are a Bachelor's Degree, 450 hours of education, five years full-time and 3000 hours of supervision.

Level III credential would equip institutional managers/directors. The criteria for eligibility are a Master's or Doctorate Degree, three letters of reference, 2000 hours of peer review for every three years of practice. Other skills, knowledge and competencies in addiction treatment, extensive research, consultations and supervisions would be expected.

The third milestone in the process of development of certification in Kenya was the Train of Trainers (TOT) which took place from 14-19 December 2009. The facilitators were Cynthia Moreno, NAADAC Executive Director and Shirley Beckett, NAADAC Director of Certification.

This training's objective was to prepare a team of core trainers, (12) that would soon be rolling out trainings to all parts of the country to not only introduce the concept of certification but also train addiction professionals on pertinent issues as learnt.

The thematic areas covered were as follows: Intake, Screening and Assessment; Referral; Treatment Planning; Documentation; Case Management; Continuing Care and Discharge; and Ethics. For their practicum, the core trainers held their first roll-out training from 15 - 27 February 2010 at NACADA's Karen office. A total of 24 persons were trained.

TOT II was conducted from $10^{\text {th }}-18^{\text {th }}$ May 2010. The topics covered during the TOT are as follows: Counselling (individual, group and family); Client education; Crisis management; and Clinical supervision. 
The second roll-out training (referred to as echo training in certain parts of the world) was conducted from August $5^{\text {th }}-11^{\text {th }} 2010$ at NACADA's Karen office.

From 5 - 16 September 2010, TOT III, the final TOT, was conducted. It covered pharmacology and also developed test items for levels II and III, in preparation for the certification examination to be conducted in future.

The first Kenyan Certification Examination was conducted in 2012. A total of 25 persons sat for the examination, with all of them scoring over $66 \%$ which is the pass mark set by PTC. This was an online examination taken at the Kenya Institute of Administration Computer lab.

The second certification examination was conducted in April 2014 at the decentralised sites in Nairobi (Kenya Institute of Administration - now known as Kenya School of Government), Mombasa (Bandari college and Eldoret (Eldoret Polytechnic) where $75 \%$ professionals were certified.

The third Certification Examination is slated for April 2015 at five different sites: Nairobi, Mombasa, Eldoret, Kisumu and Nyeri. It is expected that 120 people will sit the exam. This will be undertaken in collaboration with the Colombo Plan International Centre for Certification and Education of Addictions Professionals (ICCE). For one, this will be a cost-effective initiative reducing the examination costs by nearly $50 \%$ to make it affordable. In addition, this will offer the candidates internationally-recognised credentials. Finally, it will enhance the mutually-beneficial collaboration between the Kenya Certification Council and the ICCE.

The certification process in Kenya has come a long way. It is now guided by the Policy and Procedure Manual for Certification. ${ }^{9}$ It is hoped that other African countries, including other developing nations, will learn some things as they develop their own processes. It is encouraging to note that African countries contemplate developing an African certification system and are considering partnerships and mergers with an international certification system. This will save on costs, time and sharing of experiences. Without doubt, that will impact immensely on professionalisation of the addiction treatment field in Africa and the world. 


\section{References}

1. http://en.wikipedia.org/wiki/List_of_African_countries_by_population

2. https://www.unodc.org/documents/wdr2014/World_Drug_Report_2014_web.pdf

3. Establishment of the Asumbi, the first treatment facility in Kenya

4. Establishment of the National Campaign Against Alcohol and Drug Abuse ( NACADA)

5. American Psychological Association Dictionary of Psychology (2007) Washington DC: APA,

6. The National Standards for Treatment and Rehabilitation of Persons with Substance Use Disorders, (2009)Nairobi : Government Press

7. Perkinson R.R. "Chemical Dependency Counseling, A Practical Guide”, California :Sage Publications.2002

8. Policy and Procedure Manual for Certification of Addictions Professionals, NACADA 2012 